\title{
SUSCETIBILIDADE DE GENÓTIPOS DE Lolium multiflorum AO HERBICIDA GLYPHOSATE ${ }^{1}$
}

\author{
Susceptibility of Lolium multiflorum Genotypes to Glyphosate
}

\author{
DORS, C.A. ${ }^{2}$, CHRISTOFFOLETI, P.J. ${ }^{3}$, SANCHOTENE, D.M. ${ }^{4}$, DIAS, A.C.R. ${ }^{5}$, MANFRON, P.A. ${ }^{6}$ e \\ DORNELLES, S.H.B.7
}

\begin{abstract}
RESUMO - Objetivou-se com este trabalho avaliar o grau de tolerância dos genótipos diploides e tetraploides de L. multiflorum (azevém) ao herbicida glyphosate. Para isso, foram instalados quatro experimentos, sendo um para cada estádio fenológico do azevém (duas folhas, quatro perfilhos, pré-florescimento e formação de grãos). Utilizou-se delineamento em blocos casualizados com arranjo fatorial $2 \times 6$ (dois genótipos e seis doses do herbicida glyphosate: $240,480,960,1.920,3.840$ e 7.680 g e.a. ha ${ }^{-1}$ ) e uma testemunha sem aplicação de glyphosate, com quatro repetições. Os parâmetros analisados foram porcentagem de controle e fitomassa seca da parte aérea das plantas. Os resultados foram submetidos à análise de variância e, em seguida, ajustados para modelo de curva de dose-resposta do tipo logística, sendo desses modelos calculados valores de controle correspondentes a 50, 80, 90 e 99\%. Os genótipos de azevém diploide apresentaram suscetibilidade diferencial ao herbicida glyphosate, sendo o genótipo tetraploide mais tolerante ao herbicida que o diploide. O grau diferencial de tolerância, medido pelo fator de tolerância diferencial entre os genótipos, foi de 1,6 vez a dose de glyphosate no genótipo tetraploide em relação ao diploide. Os estádios fenológicos de desenvolvimento das plantas de ambos os genótipos afetaram o grau de tolerância ao glyphosate. A variável fitomassa seca das plantas apresentou a mesma tendência diferencial entre os genótipos diploides e tetraploides que o parâmetro porcentagem visual de controle.
\end{abstract}

Palavras-chave: azevém, inibidor da ESPS, herbicida.

ABSTRACT - This work aimed to evaluate the degree of tolerance of Italian ryegrass genotypes to the herbicide glyphosate. Thus, four experiments were installed, one for each phenological stage (two leaves, four tillers, pre-flowering, and grain formation). The treatments consisted of the combination of the two genotypes and six rates of glyphosate (240;480;960; 1,920; 3, 840 and $7,680 \mathrm{~g}$ a.e. $\mathrm{ha}^{-1}$ ) and a check without glyphosate application, in a complete randomized block design and four replications. The parameters analyzed were control percentage and shoot dry biomass. Results were submitted to analysis of variance and subsequently adjusted to non-linear log of dose-response curves, and from these models control values were calculated at 50,80,90 and 99\%. The Italian ryegrass genotypes presented differential susceptibility to the herbicide glyphosate, with the tetraploid genotype being more tolerant to the herbicide than the diploid. The degree of differential tolerance, measured by the differential tolerance factor between the genotypes, is 1.6 times the glyphosate dose in the tetraploid genotype compared to the diploid genotype. The phenological stages of plant development of both the genotypes studied affected the degree of tolerance to glyphosate. The variable shoot dry biomass presented the same differential tendency between the diploid and tetraploid genotypes presented by the parameter visual control percentage.

Keywords: Italian ryegrass, ESPS-inhibitor, herbicide

Recebido para publicação em 20.5.2009 e na forma revisada em 15.6.2010.

2 Engo-Agr ${ }^{-}$., M.Sc., Professor do Instituto Federal de Educação, Ciência e Tecnologia do Rio Grande do Sul - Campus Sertão, <celsodors@yahoo.com. br>; ${ }^{3}$ Professor Associado, Dep. de Produção Vegetal, ESALQ/USP, Av. Pádua Dias, 11 - Caixa Postal 09, 13419-900 Piracicaba-SP, <pjchrist@esalq.usp.br>; ${ }^{4}$ Enga -Agra., M.Sc., Doutoranda do Programa de Pós-graduação em Agronomia, Universidade Federal de Santa Maria-RS, UFSM, <danie.sanchotene $a$ hotmail.com $>;{ }^{5}$ Eng ${ }^{\mathrm{a}}-\mathrm{Agr}{ }^{\mathrm{a}}$.,, M.Sc., Doutoranda do Programa de Pós-Graduação em Fitotecnia da Escola Superior de Agricultura "Luiz de Queiroz" - ESALQ/USP, <anacarolina.r.dias@gmail.com>; ${ }^{6}$ Professor Titular, Dep. de Fitotecnia, UFSM, <pamanfron@hotmail.com>; ${ }^{6}$ Professor Adjunto, Departamento de Biologia, UFSM, <sylvio@smail.ufsm.br>. 


\section{INTRODUÇÃO}

O azevém (Lolium multiflorum) é a espécie forrageira de maior utilização no Rio Grande do Sul, assim como na maior parte das regiões temperadas e subtropicais do mundo, destacando-se entre as mais difundidas (Bressolin, 2007). É uma planta que apresenta excelente cultura de cobertura, com a finalidade de estabelecer o sistema de produção plantio direto ou no caso das áreas de fruticultura, podendo constituir-se em uma excelente cobertura morta na linha e na entrelinha da cultura. Essa espécie pode ser considerada uma planta daninha quando infestando áreas de culturas de cereais de inverno, como trigo, aveia e cevada; quando em condições climáticas ideais, ela pode infestar culturas de verão (Roman et al., 2004).

Buscando maior eficiência na produção, nos últimos anos vêm sendo explorados novos genótipos de azevém. Normalmente o azevém possui genótipo diploide, $\operatorname{com} 2 \mathrm{n}=14$ cromossomos, porém melhoristas desenvolveram os tetraploides, com $4 n=28$ cromossomos (Simmonds, 1976). O germoplasma de azevém utilizado pela maioria dos produtores é o diploide, mas, a fim de obter maior produtividade, têm-se usado genótipos de azevém tetraploide INIA Titán, pois, conforme Rocha et al. (2007), este genótipo apresenta ciclo vegetativo mais longo, pequeno alongamento de entrenós, elevada proporção de folhas e maior produtividade de matéria seca, com qualidade mais estável. A maioria dos genótipos tetraploides foi desenvolvida no Uruguai (Noro et al., 2003) e introduzida no Rio Grande do Sul por agropecuaristas próximos das fronteiras. Contudo, esses produtores encontram limitações na produção dessas sementes, além do maior custo para aquisição: cerca de seis a sete vezes maior do que de genótipos diploides tradicionais.

Para formar a palhada do azévem em pomares e no sistema de plantio direto, é utilizado quase que exclusivamente o glyphosate. O uso desse herbicida no controle de azevém, em áreas de plantio direto e em culturas perenes (pomares), é uma prática que vem sendo adotada há mais de 20 anos no Brasil. A preferência, por parte dos agricultores, pelo uso do glyphosate deve-se, principalmente, ao fato de que esse produto apresenta alta eficiência e custo relativamente baixo (Vargas et al., 2007).

O glyphosate pertence ao grupo de herbicidas inibidores da 5-enol-piruvil-chiquimate3-fosfato sintase (EPSPs) age inibindo esta enzima na rota de síntese dos aminoácidos aromáticos essenciais fenilalanina, tirosina e triptofano, que são precursores de outros produtos, como lignina, alcaloides, flavonoides e ácidos benzoicos (Rodrigues \& Almeida, 2005). Os sintomas das plantas sob efeito desse herbicida incluem amarelecimento dos meristemas, necrose e morte em dias ou semanas. Esse herbicida vem sendo usado de forma não seletiva, porém, com o advento das plantas transgênicas, passaram a ser opção para controle seletivo das plantas daninhas nas culturas transgênicas (Padgette et al., 1995; Arnaud et al., 1994). Possui amplo espectro de ação sobre as comunidades de plantas daninhas, atuando sobre folhas largas (magnoliopsidas) e folhas estreitas (liliopsidas) em condições de pós-emergência.

No caso de planta daninha L. multiflorum, sua recomendação de dose na formulação 480 g e.a. $L^{-1}$ é de 960 a 1.440 g e.a. ha ${ }^{-1}$, dependendo do estádio fenológico dessa planta (Rodrigues \& Almeida, 2005). Existe uma interação entre a dose do herbicida e o estádio fenológico sobre a eficácia de controle da planta daninha L. multiflorum (Ribeiro et al., 2008). Quanto mais avançado o estádio fenológico da planta daninha, maior é a dose do herbicida requerida para um controle eficiente (Christoffoleti et al., 2005); o padrão de variação de resultados segue o modelo matemático não linear (Ribeiro et al., 2008). Essa informação gerada pela pesquisa será de grande valia para os sistemas de produção no sentido de otimizar a dose aplicada, gerando um manejo da planta daninha mais econômico, de menor impacto ambiental e de forma racional.

Na literatura não são encontrados trabalhos comparativos de doses de glyphosate para controle dos genótipos diploides e tetraploides de azevém no Brasil. Assim, foi desenvolvida a presente pesquisa com o objetivo de avaliar o grau de tolerância dos genótipos diploides e tetraploides de azevém ao herbicida glyphosate. 


\section{MATERIAL E MÉTODOS}

Os experimentos foram realizados no Departamento de Fitotecnia da Universidade Federal de Santa Maria, situado na Depressão Central do Rio Grande do Sul, com coordenadas geográficas de $29^{\circ} 43^{\prime} \mathrm{S}, 53^{\circ} 43^{\prime} \mathrm{W}$ e altitude de $95 \mathrm{~m}$, durante o ano agrícola de 2007. O clima da região é o Cfa (subtropical úmido com verões quentes e sem estação seca definida), conforme classificação de Köppen (Moreno, 1961).

O solo do local é uma transição entre a Unidade de Mapeamento São Pedro (Argissolo Vermelho distrófico arênico) e a Unidade de Mapeamento Santa Maria (Alissolo Hipocrômico Argilúvico Típico) (Embrapa, 2006), apresentando $\mathrm{pH}$ água de 5,2 , teor de argila de $22 \%$, de cálcio de $1,8 \mathrm{mg} \mathrm{L}^{-1}$, de magnésio de $0,8 \mathrm{mg} \mathrm{L}^{-1}$, CTC de $76 \%$ e Al igual a $0,2 \mathrm{mg} \mathrm{L} \mathrm{L}^{-1}$.

O delineamento experimental adotado foi de blocos ao acaso com arranjo fatorial $2 \times 6$ (dois genótipos e seis doses do herbicida glyphosate). As doses aplicadas foram: 240, 480, $960,1.920,3.840$ e 7.680 g e.a. ha ${ }^{-1}$, o que equivale a $0,5,1,0,2,0,4,0,8,0$ e 16,0 L p.c. ha ${ }^{-1}$ de Roundup Transorb ${ }^{\circledR}$ ), respecivamente e uma testemunha sem aplicação de glyphosate, com quatro blocos, e dois genótipos, diploide e tetraploide. Quatro experimentos foram desenvolvidos, sendo um para cada um dos quatro estádios fenológicos do azevém (diploide e tetraploide), ajustados à escala $\mathrm{BBCH}$, discutida por Hess et al. (1997) (Tabela 1). O estádio fenológico foi definido quando $50 \%+1$ do total de plantas apresentavam determinada característica de desenvolvimento.

O genótipo diploide de azevém utilizado foi o INIA, e o genótipo tetraploide, a INIA Titán, ambos apresentando bom índice de germinação-emergência. As sementes foram coletadas na fronteira do RS com o Uruguai, em áreas sem histórico da aplicação de glyphosate. A semeadura foi realizada no dia 11 de maio de 2007 para ambos os genótipos. A correção do $\mathrm{pH}$ e a adubação do solo foram embasadas na análise de solo da área experimental, seguindo as recomendações da Comissão de Química e Fertilidade do Solo - CQFSRS/SC (2004). Em 15/2/2007 foram aplicados 3,7 $\mathrm{t} \mathrm{ha}^{-1} \mathrm{de}$ calcário (PRNT 75,4\%). Nas semeaduras foram utilizados $250 \mathrm{~kg} \mathrm{ha}^{-1}$ da formulação 12-32-16 $\left(\mathrm{N}-\mathrm{P}_{2} \mathrm{O}_{5}-\mathrm{K}_{2} \mathrm{O}\right)$. A adubação nitrogenada em cobertura foi parcelada em três vezes (início do perfilhamento, alongamento e emborrachamento), com $50 \mathrm{~kg} \mathrm{ha}^{-1}$ de $\mathrm{N}$, na forma de ureia.

O solo foi preparado pelo método convencional, e na semeadura do azevém utilizaramse $25 \mathrm{~kg} \mathrm{ha}^{-1}$ de sementes, sendo esse valor corrigido de acordo com a pureza e a germinação dos genótipos. Cada unidade experimental foi composta por um canteiro com cinco fileiras de 4,0 m de comprimento e espaçamento de $0,2 \mathrm{~m}$ entre elas.

Para as aplicações, utilizou-se de pulverizador costal pressurizado por $\mathrm{CO}_{2}$, acoplado a uma barra de pulverização com largura útil de $2 \mathrm{~m}$, com quatro pontas do tipo leque, 110.01, espaçadas de $0,50 \mathrm{~m}$, calibrado para um volume de calda proporcional a $200 \mathrm{~L} \mathrm{ha}^{-1}$.

A aplicação dos tratamentos herbicidas para o primeiro estádio fenológico (duas folhas) ocorreu no dia 2 de junho de 2007; no momento da aplicação, as condições climáticas eram de: temperatura de $12{ }^{\circ} \mathrm{C}$, umidade relativa do ar de $72 \%$ e velocidade do vento de $3,4 \mathrm{~km} \mathrm{~h}^{-1}$. A aplicação na segunda época (quatro perfilhos) ocorreu no dia 29 de junho de 2007, e as condições climáticas eram: umidade relativa do ar de $78 \%$, temperatura do ar de $19{ }^{\circ} \mathrm{C}$ e velocidade do vento de $4,4 \mathrm{~km} \mathrm{~h}^{-1}$. A aplicação da terceira época (estádio fenológico de préflorescimento) ocorreu no dia 20 de julho de 2007, e as condições climáticas no momento da aplicação eram de temperatura na faixa dos $12^{\circ} \mathrm{C}$, umidade relativa do ar de $68 \%$ e velocidade do vento de $2,7 \mathrm{~km} \mathrm{~h}^{-1}$. No dia 25 de agosto de 2007, ocorreu a aplicação dos tratamentos herbicidas para a quarta época (estádio fenológico de enchimento de grãos);

Tabela 1 - Descrição dos estádios fenológicos dos genótipos de azevém em que foram feitas as aplicações dos tratamentos herbicidas. Santa Maria-RS, 2009

\begin{tabular}{|c|l|c|}
\hline Tratamento & \multicolumn{2}{|c|}{ Estádios fenológicos da planta daninha } \\
\hline 1 & Duas folhas & $\mathrm{BBCH}^{1 /} 12$ \\
\hline 2 & Quatro perfilhos & $\mathrm{BBCH} 24$ \\
\hline 3 & Pré-florescimento & $\mathrm{BBCH} 45$ \\
\hline 4 & Formação de grãos & $\mathrm{BBCH} 65$ \\
\hline
\end{tabular}

1/ Escala fenológica discutida por Hess et al. (1997). 
as condições climáticas no momento da aplicação eram de: temperatura do ar de $13,4{ }^{\circ} \mathrm{C}$, umidade relativa do ar de $54 \%$ e velocidade do vento de $3,5 \mathrm{~km} \mathrm{~h}^{-1}$.

Os parâmetros avaliados para comparação entre os tratamentos foram: avaliação visual de controle aos 7, 14, 21 e 28 dias após a aplicação do herbicida (DAA), no respectivo estádio fenológico, e fitomassa seca das plantas daninhas aos 28 DAA. Nas avaliações de controle, utilizou-se escala da ALAM (1974), em que zero representou a ausência de sintomas e 100 a morte de todas as plantas.

Os dados foram inicialmente submetidos à aplicação do teste $\mathrm{F}$ na análise de variância. Em seguida, foram ajustados para o modelo de regressão não linear do tipo logístico, proposto por Streibig et al. (1988):

$$
y=\frac{a}{\left[1+\left(\frac{x}{b}\right)^{c}\right]}
$$

em que $y$ é o controle percentual; $x$, a dose do herbicida $\left(\mathrm{g} \mathrm{ha}^{-1}\right)$; e $a, b$, e $c$, parâmetros estimados da equação, de forma que $a$ é a amplitude existente entre o ponto máximo e o ponto mínimo da variável, $b$ é a dose que proporciona $50 \%$ de resposta da variável e $c$ é a declividade da curva ao redor de $b$.

O modelo logístico apresenta vantagens, uma vez que um dos termos integrantes da equação $(b)$ é uma estimativa do valor de $\mathrm{C}_{50}$

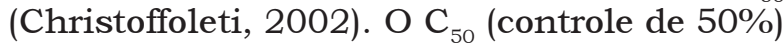
é a dose do herbicida, em gramas do ingrediente ativo por hectare, que proporciona o valor de $50 \%$ de controle ou de redução de crescimento da planta daninha (Christoffoleti, 2002; Christoffoleti \& López-Ovejero, 2008). Embora um dos parâmetros do modelo logístico $(b)$ seja uma estimativa do valor de $\mathrm{C}_{50}$, optou-se também por realizar seu cálculo matemático por meio da equação inversa, com base na discussão proposta por Carvalho et al. (2005) (Tabela 2).

\section{RESULTADOS E DISCUSSÃO}

Analisando as curvas de dose-resposta contidas na Figura 1, verifica-se que as aplicações de doses de glyphosate no estádio de duas folhas dos genótipos diploides e tetraploides de azevém proporcionaram eficácia de controle diferencial entre os genótipos. Essas diferenças evidenciam a maior suscetibilidade do fenótipo diploide ao herbicida glyphosate na dose recomendada do herbicida para o azevém (960 a 1.920 g e.a. ha ${ }^{-1}$, segundo Rodrigues \& Almeida, 2005).

Entre as principais características agronômicas apresentadas por um cultivar tetraploide de azevém, quando utilizado para fins de produção de forragem, destacam-se a rápida produção inicial e a alta produção total de fitomassa verde da forragem, além de ele apresentar um ciclo vegetativo mais longo, quando comparado com um cultivar diploide (Jensen, 2003). No entanto, essas diferenças não são constantes entre os genótipos de todas as espécies que apresentam os dois tipos de grau de ploidia. No trabalho desenvolvido por Thomas \& Murray (1978) não foi encontrada nenhuma relação entre o nivel de tolerância da planta daninha grama-seda (Cynodon dactylon) ao herbicida dalapon e o grau de ploidia da planta daninha. No entanto, a poliploidia tem sido estudada como uma das forcas evolutivas das espécies vegetais (Soltis \& Soltis, 1995). Várias respostas positivas têm sido observadas de poliploides ao estresse submetido pelo ambiente onde a planta está sobrevivendo, em comparação com diploides. Lewis (1980) destaca que poliploides são também

Tabela 2 - Parâmetros do modelo logístico para controle (\%) aos 28 DAA e coeficiente de determinação $\left(\mathrm{R}^{2}\right)$ para genótipos diploides e tetraploides de azevém submetidos à aplicação de diferentes doses do herbicida glyphosate, em quatro estádios fenológicos (BBCH). Santa Maria-RS, 2009

\begin{tabular}{|l|c|c|c|c|}
\hline \multirow{2}{*}{$\mathrm{EF}^{1 /}$} & \multicolumn{3}{|c|}{ Parâmetro - Modelo Logístico ${ }^{-/}$} & \multirow{2}{*}{$\mathrm{R}^{2}$} \\
\cline { 2 - 4 } & $\mathrm{a}$ & $\mathrm{b}$ & $\mathrm{c}$ & \\
\hline & 100 & 356,10 & $-3,40$ & 0,95 \\
\hline 2 folhas & 100 & 622,54 & $-2,29$ & 0,98 \\
\hline 4 Perfilhos & 100 & 441,23 & $-1,68$ & 0,95 \\
\hline Pré-florescimento & 100 & 663,80 & $-1,38$ & 0,99 \\
\hline Formação de grãos & \multicolumn{3}{|c|}{ Tetraploide } \\
\hline & 100 & 625,36 & $-2,63$ & 0,95 \\
\hline 2 folhas & 100 & 823,32 & $-2,16$ & 0,99 \\
\hline 4 Perfilhos & 100 & 809,74 & $-1,72$ & 0,98 \\
\hline Pré-florescimento & 100 & $1.019,10$ & $-1,51$ & 0,99 \\
\hline Formação de grãos &
\end{tabular}

${ }^{1 /}$ EF: estádio fenológico; ${ }^{2 /}$ Modelo: $\mathrm{y}=\left(\mathrm{a} /\left(1+(\mathrm{x} / \mathrm{b})^{\mathrm{c}}\right)\right)$ 


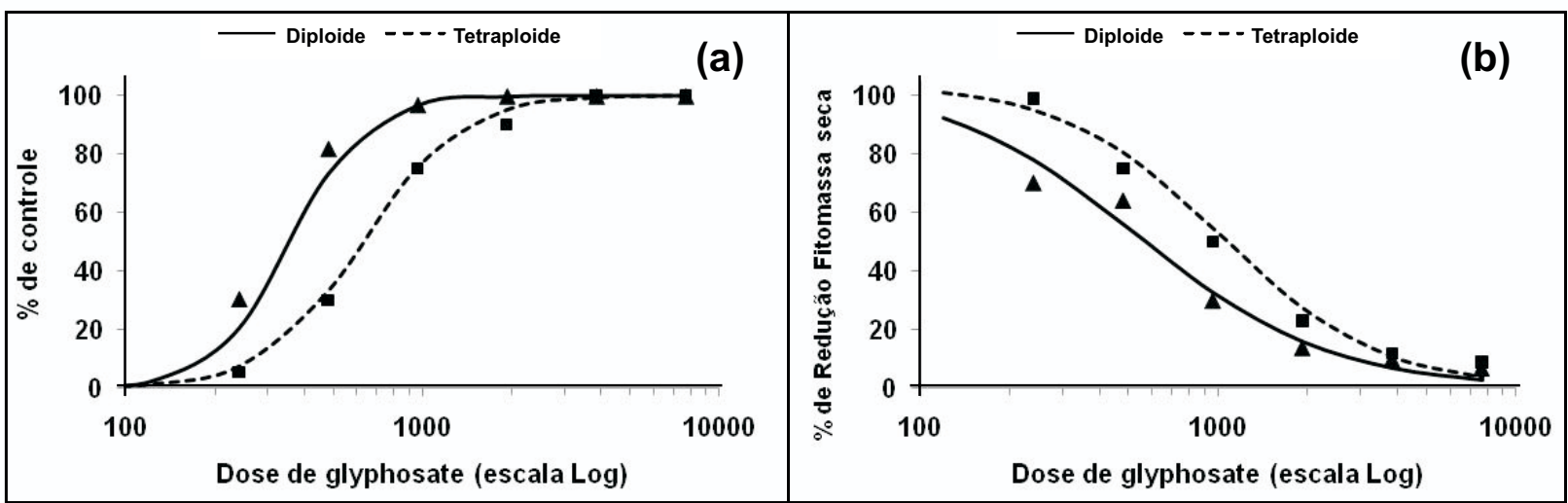

Figura 1 - Efeito de doses de glyphosate no controle (a) e na fitomassa seca (b) aos 28 DAA de genótipos diploide e tetraploide de azevém, aplicadas no estádio de duas folhas (BBCH 12). Santa Maria-RS, 2009.

mais tolerantes a herbicidas, sendo esta tolerância relacionada com o aumento de heterozigose e redundância genética.

As doses de glyphosate necessárias para controle de $50 \%$ dos genótipos apresentados na Tabela 3 (valores de $b$ da equação não linear) no estádio de duas folhas indicam que há necessidade de acréscimo de 1,76 vez na dose (FT) para o genótipo tetraploide. Assim, fica evidente que o genótipo apresenta tolerância maior ao glyphosate. Consequentemente, para obtenção de resultados de controle satisfatórios deste genótipo no processo de dessecação é necessário doses maiores em comparação com o genótipo diploide, conforme pode ser observado na Tabela 5. Para obter os mesmos índices de controle, o genótipo tetraploide necessita de 2,$10 ; 2,33 ; 2,57$; e 3,19 vezes a dose utilizada no genótipo diploide para obtenção de eficácia de controle de 80 , 90, 95 e 99\%, respectivamente (Tabela 5).

Segundo Vargas et al. (2006), o glyphosate é um herbicida de amplo espectro, utilizado há mais de 15 anos em pomares de maçã na região de Vacaria-RS para manejo da vegetação nas linhas da cultura, onde o azevém é uma planta daninha predominante durante o período de inverno. São realizadas, em geral, três a quatro aplicações por ciclo, e a dose normalmente utilizada está entre 720 e 1.080 g e.a. ha ${ }^{-1}$ de glyphosate. Segundo os resultados da presente pesquisa (Tabela 5), para o controle do genótipo tetraploide a dose recomendada para o controle de azevém no Rio Grande do Sul não atingiria, no estádio de duas
Tabela 3 - Parâmetro $b$ do modelo logístico para controle aos 28 DAA e fator de tolerância (FT) dos genótipos diploides e tetraploides de azevém, em função do estádio fenológico de aplicação do glyphosate. Santa Maria-RS, 2009

\begin{tabular}{|l|c|c|c|c|}
\hline \multirow{2}{*}{ Genótipo } & \multicolumn{4}{|c|}{ Estádio fenológico de aplicação do glyphosate } \\
\cline { 2 - 5 } & 2 folhas & 4 Perfilhos & $\begin{array}{c}\text { Pré-floresci- } \\
\text { mento }\end{array}$ & $\begin{array}{c}\text { Formação } \\
\text { de grãos }\end{array}$ \\
\hline Diploide & $356,10^{1 /}$ & 622,54 & 441,23 & 663,8 \\
\hline Tetraploide & 625,36 & 823,32 & 809,74 & $1.019,1$ \\
\hline FT $^{2 /}$ & 1,76 & 1,32 & 1,83 & 1,53 \\
\hline
\end{tabular}

${ }^{1}$ Valores de $b$ (g e.a. ha ${ }^{-1}$ de glyphosate), que representam o $\mathrm{C}_{50}$ 2 FT - Fator de tolerância entre os genótipos diploide e tetraploide submetidos à aplicação de glyphosate, calculado a partir da razão dos valores de $b$ do genótipo tetraploide pelo genótipo diploide.

Tabela 4 - Parâmetros do modelo logístico para fitomassa seca aos 28 DAA e coeficiente de determinação $\left(\mathrm{R}^{2}\right)$ para genótipos diploides e tetraploides de azevém submetidos à aplicação de diferentes doses do herbicida glyphosate, em quatro estádios fenológicos (BBCH). Santa Maria-RS, 2009

\begin{tabular}{|l|c|c|c|c|}
\hline \multirow{2}{*}{$\mathrm{EF}^{1 /}$} & \multicolumn{3}{|c|}{ Parâmetro - Modelo Logístico ${ }^{2 /}$} & \multirow{2}{*}{$\mathrm{R}^{2}$} \\
\cline { 2 - 4 } & $\mathrm{a}$ & $\mathrm{b}$ & $\mathrm{c}$ & \\
\hline & 105 & 533,20 & 1,34 & 0,90 \\
\hline 2 folhas & 105 & 617,90 & 1,46 & 0,87 \\
\hline 4 Perfilhos & 104 & 618,60 & 1,13 & 0,94 \\
\hline Pré-florescimento & 104 & 573,20 & 2,07 & 0,97 \\
\hline Formação de grãos & \multicolumn{3}{|c|}{ Tetraploide } \\
\hline & 104 & $1.022,40$ & 1,63 & 0,95 \\
\hline 2 folhas & 105 & $1.365,00$ & 1,65 & 0,95 \\
\hline 4 Perfilhos & 104 & $1.137,00$ & 1,62 & 0,98 \\
\hline Pré-florescimento & 100 & $1.535,14$ & 2,16 & 0,98 \\
\hline Formação de grãos & 100 &
\end{tabular}

${ }^{1 /}$ EF: estádio fenológico; ${ }^{2 /}$ Modelo: $\mathrm{y}=\left(\mathrm{a} /\left(1+(\mathrm{x} / \mathrm{b})^{\mathrm{c}}\right)\right)$. 
Tabela 5 - Doses de glyphosate em g e.a. ha ${ }^{-1}$ necessárias para os respectivos controles, calculadas por meio do modelo logístico ajustado para os dados das curvas de dose-resposta dos genótipos diploides e tetraploides de azevém, aplicadas no estádio de duas folhas (BBCH 12). Santa Maria-RS, 2009

\begin{tabular}{|c|c|c|c|}
\hline \% Controle & Diploide (D) & Tetraploide (T) & T/D \\
\hline 99 & $1.375,7$ & $4.382,7$ & 3,19 \\
\hline 95 & 846,6 & $2.177,6$ & 2,57 \\
\hline 90 & 679,6 & $1.586,6$ & 2,33 \\
\hline 80 & 535,4 & $1.125,2$ & 2,10 \\
\hline $50^{1 /}$ & 356,1 & 625,4 & 1,76 \\
\hline
\end{tabular}

1/ Representa o valor do parâmetro b da equação da curva de doseresposta utilizada na representação gráfica dos dados obtidos $\left(\mathrm{C}_{50}\right)$.

folhas, o valor minimo exigido de $80 \%$ (Brasil, 2009), pois para isso seria necessária uma dose mínima de 1.125 g e.a. ha ${ }^{-1}$ (Tabela 5).

Na Figura 2 estão apresentados os resultados de controle do segundo estádio fenológico de aplicação de dois perfilhos (BBCH 24). É possivel observar que também nesse estádio existe eficácia de controle diferencial dos genótipos pelo glyphosate, porém em menor intensidade. No entanto, analisando a Tabela 3 , verifica-se que os valores de $C_{50}$ (valores de $b$ da equação não linear) tiveram dimensão maior que o primeiro estádio de aplicação, indicando que, de modo geral, os dois genótipos apresentaram tolerância maior que o estádio fenológico BBCH 12. Essa informação também pode ser visualizada na Tabela 6 , onde se observa que para um controle de 90\% do azevém tetraploide é necessária uma dose de $2.276,9$ g e.a. ha ha $^{-1}$ e para o diploide, $1.625,1$ g e.a. ha ${ }^{-1}$. De acordo com Rodrigues \& Almeida (2005), a dose máxima recomendada do herbicida glyphosate para o azevém é de 1.920 g e.a. ha-1; assim, para o genótipo tetraploide não é possível, no estádio fenológico de quatro perfilhos, obter controles da ordem de $90 \%$, conforme exigem algumas situações de alta pressão de infestação de azevém nos sistemas agrícolas (observações práticas).

Christoffoleti et al. (2005), estudando a expressão da resistência ao glyphosate em relação ao estádio de desenvolvimento do Lolium multiflorum, concluíram que: i) quanto mais avançado o estádio fenológico da planta daninha no momento da aplicação, maiores dificuldades de controle pelas doses menores de glyphosate são obtidas, principalmente na dose de 960 g e.a. ha ${ }^{-1}$; no entanto, nessa dose e nos estádios de duas folhas a cinco perfilhos, o controle foi superior a $90 \%$, apresentando rebrota posteriormente; e ii) com o incremento da dose de glyphosate, observou-se resposta significativa no controle em todos os estádios fenológicos da planta daninha no momento da aplicação do herbicida.

As curvas de dose-resposta (Figura 3, Tabelas 2 e 4) evidenciam a resposta dos genótipos de azevém quando submetidos à aplicação de doses do herbicida glyphosate no estádio fenológico de pré-florescimento (BBCH 45). Da mesma forma que nos dois estádios anteriores, observa-se que há uma diferença de resposta entre as curvas de controle do diploide e tetraploide, sendo este mais tolerante que o

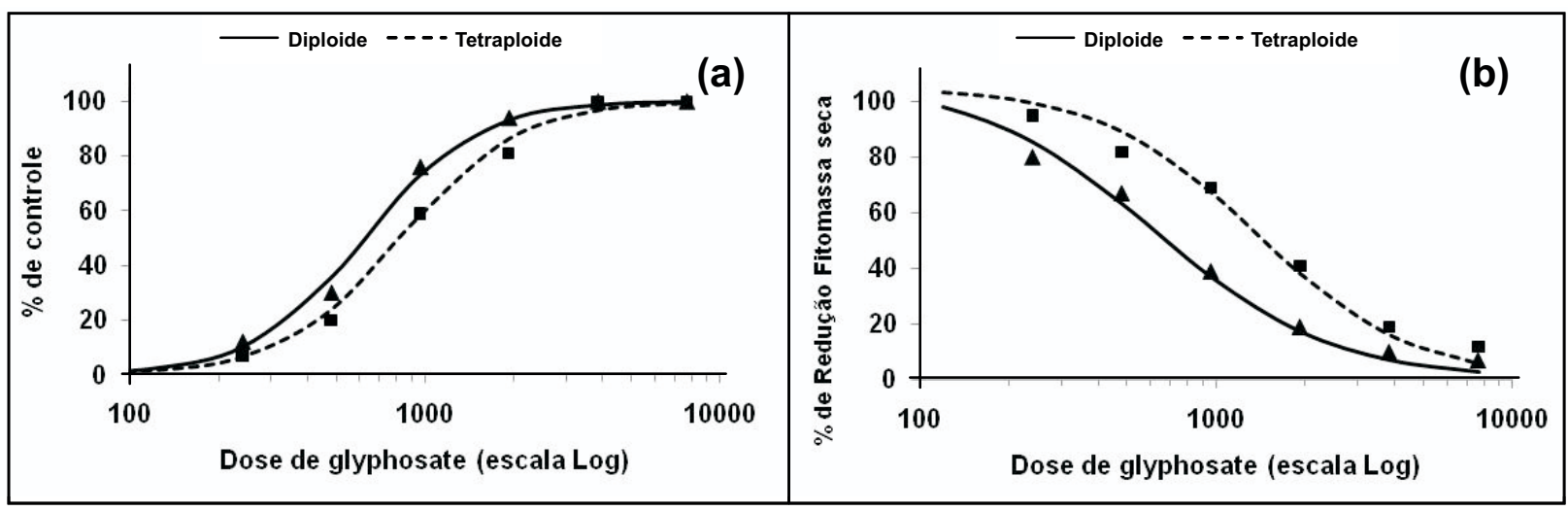

Figura 2 - Efeito de doses de glyphosate no controle (a) e na fitomassa seca (b) aos 28 DAA de genótipos diploide e tetraploide de azevém, aplicadas no estádio de duas folhas (BBCH 24). Santa Maria-RS, 2009. 
Tabela 6 - Doses de glyphosate em g e.a. ha ${ }^{-1}$ necessárias para os respectivos controles, calculadas pelo modelo logístico ajustado para os dados das curvas de dose-resposta dos genótipos diploides e tetraploides de azevém, aplicadas no estádio de quatro perfilhos (24). Santa Maria-RS, 2009

\begin{tabular}{|c|c|c|c|}
\hline \% Controle & Diploide (D) & Tetraploide (T) & T/D \\
\hline 99 & $4.630,5$ & $6.909,9$ & 1,49 \\
\hline 95 & $2.252,0$ & $3.218,0$ & 1,43 \\
\hline 90 & $1.625,1$ & $2.276,9$ & 1,40 \\
\hline 80 & $1.140,4$ & $1.564,2$ & 1,37 \\
\hline $50^{1 /}$ & 622,5 & 823,3 & 1,32 \\
\hline
\end{tabular}

primeiro. Essa maior suscetibilidade do diploide pode ser observada pelo valor de $b$ (Tabelas 3 e 7). É interessante observar que os valores de $b$ dos dois genótipos no estádio de quatro perfilhos (BBCH 24) foram superiores aos valores de $b$ obtidos para os genótipos no estádio de pré-florescimento (BBCH 45) (Tabelas 2 e 4). Uma possivel explicação para esse resultado é que no estádio de pré-florescimento o transporte de solutos é maior e direcionado para a formação de órgãos reprodutivos, interferindo na relação fonte/dreno da planta. Consequentemente, há aumento no transporte do herbicida pela planta, diminuindo a capacidade desta em metabolizar outras moléculas presentes; assim, as plantas ficam mais suscetiveis a fatores bióticos e abióticos (Lincoln \& Zeiger, 2009).

Diversos estudos têm mostrado que a distribuição de glyphosate nas plantas é proporcional e no mesmo sentido dos fotoassimilados em muitas espécies de plantas (Gougler \& Geiger, 1981), geralmente seguindo o padrão fonte-dreno. Dessa forma, existe uma grande possibilidade de a translocação do glyphosate intensificar-se durante o início do desenvolvimento floral das plantas (pré-florescimento), pois estas servem de um dreno metabólico na planta, explicando assim o menor valor de $\mathrm{C}_{50}$ no estádio de pré-florescimento (Tabelas 2 e 4) em relação ao estádio de quatro perfilhos (Tabela 4), obtido por esta pesquisa. No entanto, a mesma tendência de menores doses do glyphosate não foi observada quando o nível de controle desejado foi maior (80 a 99\%, comparando as Tabelas 5 e 6).

Analisando as curvas apresentadas na Figura 4, verifica-se que o genótipo de azevém tetraploide mostrou-se mais tolerante à aplicação de glyphosate no estádio de formação de grãos (BBCH 65). Essa tolerância é verificada

Tabela 7 - Doses de glyphosate em g e.a. ha-1 necessárias para os respectivos controles, calculadas pelo modelo logístico ajustado para os dados das curvas de dose-resposta dos genótipos diploides e tetraploides de azevém, aplicadas no estádio de pré-florescimento (BBCH 45). Santa Maria-RS, 2009

\begin{tabular}{|c|c|c|c|}
\hline \% Controle & Diploide (D) & Tetraploide (T) & T/D \\
\hline 99 & $6.800,5$ & $11.711,1$ & 1,72 \\
\hline 95 & $2.545,8$ & $4.485,5$ & 1,76 \\
\hline 90 & $1.631,8$ & $2.904,9$ & 1,78 \\
\hline 80 & $1.007,0$ & $1.812,9$ & 1,80 \\
\hline $50^{1 /}$ & 441,2 & 809,7 & 1,84 \\
\hline
\end{tabular}

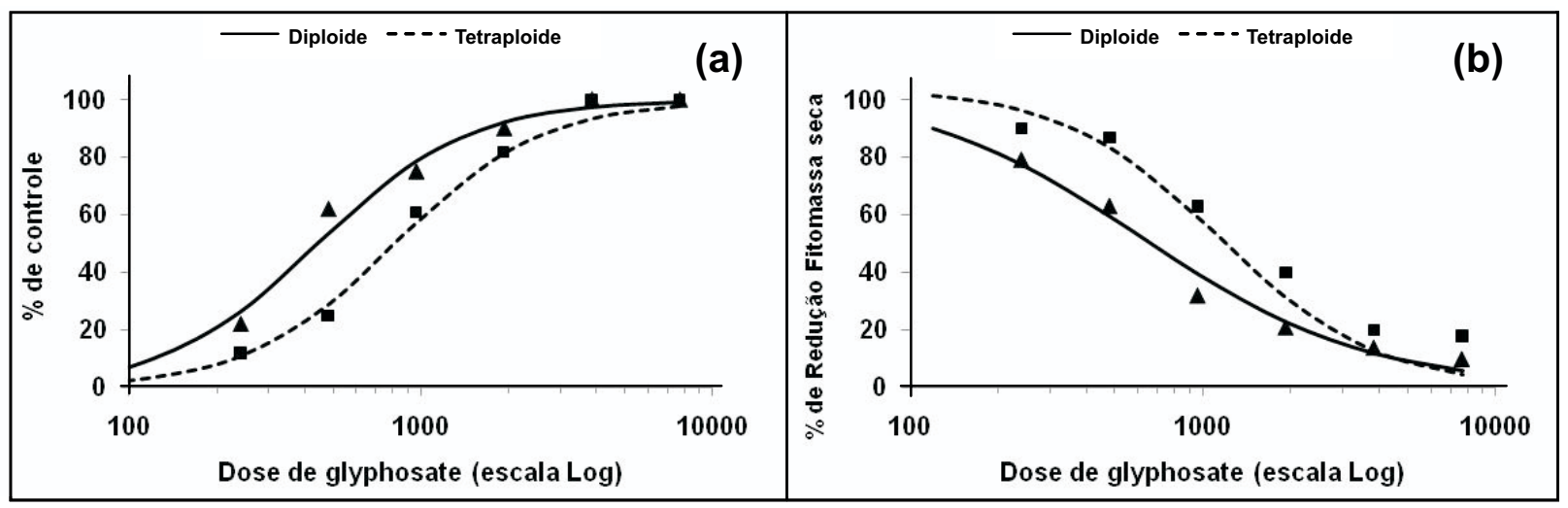

Figura 3 - Efeito de doses de glyphosate no controle (a) e na fitomassa seca (b) aos 28 DAA de genótipos diploide e tetraploide de azevém, aplicadas no estádio de duas folhas (BBCH 45). Santa Maria-RS, 2009. 
Tabela 8 - Doses de glyphosate em g e.a. ha ${ }^{-1}$ necessárias para os respectivos controles, calculadas por meio do modelo logístico ajustado para os dados das curvas de dose-resposta dos genótipos diploides e tetraploides de azevém, aplicadas no estádio de formação de grãos (BBCH 65). Santa Maria-RS, 2009

\begin{tabular}{|c|c|c|c|}
\hline \% Controle & Diploide (D) & Tetraploide (T) & T/D \\
\hline 99 & $18.541,7$ & $21.371,2$ & 1,15 \\
\hline 95 & $5.606,2$ & $7.162,6$ & 1,28 \\
\hline 90 & $3.262,3$ & $4.366,8$ & 1,34 \\
\hline 80 & $1.812,6$ & $2.552,3$ & 1,41 \\
\hline $50^{1 /}$ & 663,8 & $1.019,1$ & 1,54 \\
\hline
\end{tabular}

através dos valores de b, sendo estes de 663,8 e $1.019,1$ g e.a. ha ${ }^{-1}$ de glyphosate, respectivamente para os genótipos diploide e tetraploide (Tabela 3). Verifica-se que nesta época de aplicação (formação de grãos) do glyphosate, ambos os genótipos de azevém foram mais tolerantes ao herbicida. Este fato pode estar relacionado à fase de desenvolvimento da planta no momento da aplicação, pois nessa época o azevém encontrava-se no final do ciclo produtivo; assim, apresentava maior porte e maior número de folhas e perfilhos. Hipoteticamente, o transporte de solutos pela planta é menor, dificultando a ação do glyphosate.

Trabalhos na literatura têm evidenciado que a translocação do glyphosate nas plantas é proporcional à sua absorção. Segundo Sprankle et al. (1975), em plantas anuais que se encontram em estádios fenológicos de maturação das sementes a translocação limitada de fotossintetizados limita a eficácia do glyphosate. Da mesma forma, as plantas daninhas tolerantes ao herbicida glyphosate, como a trapoeraba e corda-de-viola, estudadas por Monquero (2004), têm na translocação eficiente o principal fator que regula a eficácia do herbicida nas plantas.

A visualização da tolerância do genótipo tetraploide sobre o genótipo diploide é observada a partir de um coeficiente, denominado de fator de tolerância (FT). Observa-se, que independentemente da época de aplicação do glyphosate, o genótipo tetraploide mostrou-se mais tolerante à ação desse herbicida quando comparado ao genótipo diploide $(\mathrm{FT}=1,53)$, ou seja, para obter o mesmo efeito biológico nas plantas de azevém tetraploide, é necessário $1,5 \mathrm{vez}$ a dose de glyphosate utilizada para controle do genótipo diploide.

Os resultados de redução de fitomassa seca (Figuras 1 a 4) também demonstraram a maior capacidade de tolerar doses de glyphosate pelas plantas de azevém de genótipos tetraploides.

Conclui-se que os genótipos de azevém diploide apresentam suscetibilidade diferencial ao herbicida glyphosate, sendo o genótipo tetraploide mais tolerante ao herbicida que o diploide. O grau diferencial de tolerância, medido pelo fator de tolerância diferencial entre os genótipos, é de 1,5 vez a dose de glyphosate no genótipo tetraploide, em relação ao diploide. Os estádios fenológicos das plantas de ambos os genótipos afetam o grau de tolerância ao glyphosate, ou seja, em estádios

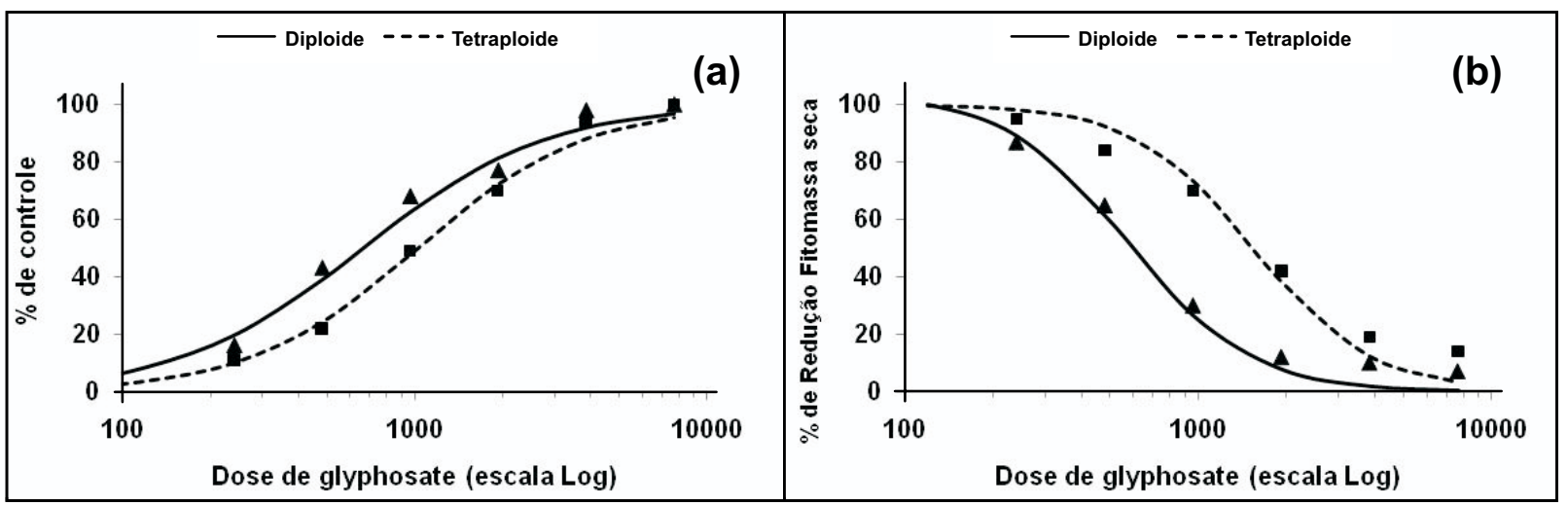

Figura 4 - Efeito de doses de glyphosate no controle (a) e na fitomassa seca (b) aos 28 DAA de genótipos diploide e tetraploide de azevém, aplicadas no estádio de duas folhas (BBCH 65). Santa Maria-RS, 2009. 
mais avançados de desenvolvimento dos dois genótipos a suscetibilidade do azevém é menor ao glyphosate, exceto para o estádio de préflorescimento, no qual a planta é mais suscetível que o estádio de quatro perfilhos.

\section{LITERATURA CITADA}

ASOCIATION LATINO AMERICANA DE MALEZAS ALAM. Recomendaciones sobre unificacíon de los sistemas de evaluación en ensayos de control de malezas. ALAM, v. 1, p. $35-38,1974$.

ARNAUD, L. et al. Distribution of glyphosate and its target enzyme inside wheat plants. Pest. Sci., v. 40, n. 3, p. 217-223, 1994.

BERSOLIN, A. P. S. Avaliação de populações de azevém quanto à tolerância no alumínio tóxico e estimativa de tamanho de amostra para estudos de diversidade genética com marcadores AFLP. 2007. 76 f. Dissertação (Mestrado em Agronomia) - Universidade Federal de Pelotas, Pelotas, 2007.

BRASIL. Ministério da Agricultura, Pecuária e Abastecimento. AGROFIT. Disponível em: $<$ http://agrofit.agricultura.gov.br/ agrofit_cons/principal_agrofit_cons $>$ Acesso em: 23 jan. 2009.

CARVALHO, S. J. P. et al. Curvas de dose-resposta para avaliação do controle de fluxos de emergência de plantas daninhas pelo herbicida imazapic. Planta Daninha, v. 23, n. 3, p. 535-542, 2005.

CHRISTOFFOLETI, P. J. Curvas de dose-resposta de biótipos resistente e suscetível de Bidens pilosa L. aos herbicidas inibidores da ALS. Sci. Agric., v. 59, n. 3, p. 513-519, 2002.

CHRISTOFFOLETI, P. J.; LÓPEZ-OVEJERO, R. F. Resistência de plantas daninhas a herbicidas: definições, bases e situação no Brasil e no mundo. In: CHRISTOFFOLETI, P. J. (Coord.). Aspectos de resistência de plantas daninhas a herbicidas. 3.ed. Piracicaba: Associação Brasileira de Ação a Resistência de Plantas aos Herbicidas, 2008. p. 9-29.

CHRISTOFFOLETI, P. J. et al. Alternative herbicides to manage Italian ryegrass (Lolium multiflorum Lam.) resistant to glyphosate at different phenological stages. J. Environ. Sci. Health. Part B, Pest. Food Contam. Agric. Wastes, v. B40, n. 1, p. 59-67, 2005.

COMISSÃO DE QUÍMICA E FERTILIDADE DO SOLO RS/SC - CQFS-RS/SC. Manual de adubação e de calagem para o Estado do Rio Grande do Sul e Santa Catarina. Porto Alegre, SBCS/Núcleo Regional Sul, UFRGS, 2004. 400 p.

EMPRESA BRASILEIRA DE PESQUISAAGROPECUÁRIA - EMBRAPA. Centro Nacional de Pesquisa de Solos. Sistema brasileiro de classificação de solos. Rio de Janeiro: 2006. 306 p.
GOUGLER, J. A.; GEIGER, D. R. Uptake and distribution of N-phosphonomethyl Glycine in sugarbeet plants. Plant Physiol., v. 68, n. 3, p. 668-672, 1981.

HESS, M. et al. Use of the extended BBCH scale - general for the descriptions of the growth stages of mono- and dicotyledonous weed species. Weed Res., v. 37, p. 433-441, 1997.

JENSEN, K. B. et al. Forage nutritional characteristics of orchardgrass and perennial ryegrass at five irrigation levels. Agron. J., v. 95, n. 3, p. 668-675, 2003.

LEWIS, W. H. (Ed). Polyploidy: biological relevance. New York: Plenum Press, 1980. 583 p.

LINCOLN, T:; ZEIGER, E. Fisiologia vegetal. 4.ed. São Paulo: Artmed, 2009. 820 p.

MONQUERO, P.A. et al. Absorção, translocação e metabolismo do glyphosate por plantas tolerantes e suscetíveis a este herbicida. Planta Daninha, v. 22, n. 3, p. 445-451, 2004.

MORENO, J. A. Clima do Rio Grande do Sul. Porto Alegre: Secretaria da Agricultura do Estado do Rio Grande do Sul, Diretoria de Terras e Colonização, Secção de Geografia. 1961. $42 \mathrm{p}$.

NORO, G. et al. Gramíneas anuais de inverno para produção de forragem: avaliação preliminar de cultivares. Agrociência, v. 7, n. 1, p. 35-40, 2003

PADGETTE, S. R. et al. Development, identification, and characterization of a glyphosate tolerant soybean line. Crop Sci., v. 35, p. 1451-1461, 1995.

RIBEIRO, D. N. et al. Rapid assays for detection fo glyphosate-resistant Lolium spp. J. Plant Deseases Protec., v. 21, n. 1 , p. $95-99,2008$

ROCHA, M. G. et al. Avaliação de espécies forrageiras de inverno na Depressão Central do Rio Grande do Sul. R. Bras. Zootec., v. 36, n. 6, p. 1990-1999, 2007.

RODRIGUES, B. N.; ALMEIDA, F. S. Guia de herbicidas. 5.ed. Londrina: IAPAR, 2005. $592 \mathrm{p}$

ROMAN, E. S. et al. Resistência de azevém (Lolium multiflorum) ao herbicida glyphosate. Planta Daninha, v. 22, n. 2, p. 301-306, 2004

SIMMONDS, N. W. Evolution of crop plants. London: Longman, 1976. 339 p.

SOLTIS, D. E.; SOLTIS, P. S. The dynamic nature of polyploid genomes. Proc. Nat. Acad. Sci., v. 92, n. 18, p. 8089-8091, 1995.

Planta Daninha, Viçosa-MG, v. 28, n. 2, p. 401-410, 2010 
SPRANKLE, P.; MEGGIT, W. F.; PENNER, D. Effect of diluents volume and calcium on glyphosate phytotoxicity. Weed Sci., v. 23, n. 3, p. 224-228, 1975.

STREIBIG, J. C. Herbicide bioassay. Weed Res., v. 28, p. 479-484, 1988.

THOMAS, S. M.; MURRAY, B. G. Herbicide tolerance and Polyploidy in Cynodon dactylon (L.) Pers. (Gramineae) Ann. Bot., v. 42, p. 137-143, 1978.
VARGAS, L. et al. Manejo de azevém resistente ao glyphosate em pomares de maçã com o herbicida Select (clethodim). R. Bras. Herbic., v. 1, n. 1, p. 30-36, 2006.

VARGAS, L.; MORAES, R. M. A.; BERTO, C. M.

Herança da resistência de azevém (Lolium multiflorum) ao glyphosate. Planta Daninha, v. 25, n. 3, p. 567-571, 2007. 